\title{
PREVALENCE AND RISK FACTOR OF CARPAL TUNNEL SYNDROME AMONG WORKERS IN THE CONSTRUCTION INDUSTRY
}

\author{
By \\ ${ }^{1}$ Abdellah RF, ${ }^{2}$ Morsy KM and ${ }^{2}$ Elshaboury I \\ ${ }^{1}$ Department of Community, Environment and Occupational Medicine ${ }^{2}$ Department of Emergency Medicine, \\ Faculty of Medicine, Suez Canal University, Ismailia, Egypt .
}

\begin{abstract}
Introduction: In terms of lost-work time, restricted workdays and rehabilitation, one of the most costly occupational musculoskeletal disorders is carpal tunnel syndrome (CTS). Aim of work: determination of CTS prevalence and evaluation of some personal and occupational risk factors among construction workers. Materials and Methods: In this descriptive cross-sectional study, 116 cases were enrolled. A questionnaire was used to assess socio-demographic data, and occupational history. CTS was assessed by symptoms on the Katz hand diagram and physical examination. Phalen's test was done for all participants. Results: According to this study, the prevalence of CTS was $27.6 \%$ among workers in construction industry. The rate of CTS was significantly higher among electricians than in other workers $(\mathrm{P}<0.05)$. The risk of developing CTS increase with age $\geq 30$ years and work duration $\geq 5$ years. Conclusion: Our findings suggest that construction workers are at an increased risk of CTS, so awareness should be raised and interventions should specifically target this risk group.
\end{abstract}

Key words: Construction workers, Carpal tunnel syndrome, Risk factors, Katz hand diagram and Phalen's test. 


\section{Introduction}

Carpal tunnel syndrome (CTS) is one of the most common nontraumatic peripheral nerve lesion and repetitive trauma disorder. It is one of the most expensive upper-extremity musculoskeletal disorders as an estimated cost of medical care, and surgical releases (Harris-Adamson et al., 2015). The non-medical costs are substantially greater. The median lost work-time from work-related CTS is 27 days, which is longer than any other work-related disorder except fractures. Furthermore, $18 \%$ of workers who develop CTS reported leaving their job within 18 months (Dale et al., 2013).

CTS arises from compression of the median nerve where it passes through the carpal tunnel in the wrist. It is characterized mainly by sensory and, to some extent, motor symptoms and signs in the peripheral distribution of the median nerve. Known causes include trauma, pregnancy, rheumatoid arthritis, diabetes, and hypothyroidism (Barcenilla et al., 2012). Since many of the individual risk factors of CTS are less modifiable than workplace factors, information about the occupations in which workers develop CTS is essential to target prevention strategies (Roquelaure et al., 2008).

Repetition of wrist flexion and extension is the greatest and the most accepted occupational risk factor. Forceful grip with the hand, and/or vibrations of the hand and arm, such as are induced by hand-held vibrating tools, can damage the median nerve and cause CTS. Frequency of the task and the percentage at the time spent on the repetitive task are important (Ghasemi et al, 2012). Moreover, repetitive wrist movements lasting more than 30 seconds and working more than $50 \%$ of total work time in repetitive movement patterns are considered significant (Silverstein et al., 1987).

Construction industry involves many types of activities aside from the building process, such as landscaping, painting, electrical supply, plastering, paving and telecommunications. Construction work involves a serious of occupational risks, such as work at heights (use of scaffolding, gangways and ladders), excavation work (use of earth-moving machines and explosives), materials lifting (use of cranes) and so 
on (Adane et al., 2013). Occupational injuries and accidents among these workers are high due to illiteracy and lack of health safety training and information on health hazards and risks at the work place (Foley et al., 2007). Musculoskeletal disorders are a main cause of productivity loss at work, functional impairments and permanent disability (Boschman et al., 2015).

The estimate incidence and prevalence of CTS vary widely in the literature. The annual incidence rates were between 0.5 and 5.1 per 1,000 for CTS defined by electrophysiological criteria and 0.4 to 1.5 per 1,000 for CTS requiring surgical release of the median nerve (Roquelaure et al., 2008). Its incidence in the workplace has reached epidemic proportions as it comprise about $40.8 \%$ of all upper extremity repetitive motion disorders (Jagga et al, 2011). Prevalence estimates of CTS in the general adult population range from approximately $1 \%$ to $16 \%$ (Raman et al., 2012). In German, the prevalence of CTS in working populations (10.9\%) was significantly higher than in the general population $(8.2 \%)$ (Spahn et al., 2012).
The construction sector in Egypt is a major contributor to the country's economy and one of its fastest-growing sectors. Little work has been done on occupational health and safety aspects of building construction workers and there is lack of data about prevalence and determinant factors of CTS among these workers. Therefore, the present study attempted to contribute in determining magnitude and factors related to CTS among building construction workers in Ismailia city, Egypt.

\section{Aim of work}

Determination of CTS prevalence and evaluation of some personal and occupational risk factors among construction workers.

\section{Materials and Methods}

- Study design: It is a cross sectional study.

- Place and duration of study: This study was carried out on workers in the construction industry in Ismailia city during the period from February to April 2015.

- Study sample: the required sample size was determined by using EPIINFO program version 7 (Dean et 
al, 2001). For the calculation, $95 \%$ confidence level, $5 \%$ marginal error and $8.2 \%$ prevalence were taking from a previous study (Ghasemi et al, 2012).

\section{- Study methods:}

Workers were recruited in the study according to the following inclusion criteria; working in the construction industry for at least 1 year, with no past history of chronic diseases or disability. Exclusion criteria included workers with a history of certain disorders such as rheumatoid arthritis, diabetes mellitus, cervical radiculopathy, hypothyroidism, thoracic outlet syndrome and medically diagnosed CTS prior to starting the current occupation.

A questionnaire was prepared in English and translated to Arabic (native language) and then back to English by different independent language experts to verify the consistency and content of translation. Detailed information about the socio-demographic, and occupational data as: age, marital status, education, residence, job category, duration of work in years and working hours were included.
The diagnosis of CTS was based on the NIOSH criteria for definition, namely the presence of: (i) one or more symptoms indicative of CTS, e.g. paraesthesiae, pain or numbness; and (ii) clinical signs that included a positive Tinel's sign or Phalen's sign or nerve conduction findings indicative of nerve dysfunction across the carpal tunnel as well as (iii) evidence of work relatedness or the development of symptoms proceeding after employment in a job involving one or more activities such as the use of hand force, repetitive motion, use of vibrating tools and awkward positions (Sluiter et al, 2011).

\section{Data analysis:}

The data were entered, cleaned and analyzed using SPSS software version 13.0. Descriptive statistics like frequency distribution and percentage calculation was made for most of the variables. Chi-Square test was used to examine the relationship between two qualitative variables, Fisher $>$ s exact test was used to examine the relationship between two qualitative variables when there $>$ a cell with an expected frequency of less than 5. Bivariate analysis was carried out to identify risk factors in 
terms of unadjusted odds ratios (OR) Funding:

with their 95\% confidence intervals (CIs). A $\mathrm{P}<0.05$ was considered statistically significant.

No funding sources for this research.

\section{Consent}

The study subjects were explained the purpose of study, assured privacy and a verbal consent was obtained from them.

\section{Ethical Approval:}

Confidentiality and anonymity were maintained according to the regulations mandated by Research Ethics Committee of Faculty of Medicine Suez Canal University. 


\section{Results}

This study was carried in Ismailia city on 116 of workers in construction industry.

Table 1. Distribution of the study group according to socio-demographic characteristics

\begin{tabular}{|l|c|c|}
\hline Socio-demographic characteristics & No. & $\%$ \\
\hline Age (yrs) & 20 & 17.2 \\
$<20$ & 51 & 44.0 \\
$20-40$ & 45 & 38.8 \\
$>40$ & \multicolumn{2}{|c|}{} \\
\hline mean \pm SD & \multicolumn{2}{|c|}{$26.6 \pm 8.6$} \\
\hline Residence & 66 & 56.9 \\
Urban & 50 & 43.1 \\
Rural & & \\
\hline Marital status & 61 & 52.6 \\
Single & 55 & 47.4 \\
Married & & \\
\hline Education & & \\
Illiterate & 23 & 19.8 \\
Primary \& preparatory & 38 & 32.8 \\
Secondary \& technical & 55 & 47.4 \\
\hline Smoking habits & 60 & 51.7 \\
Non-smoker & 56 & 48.3 \\
Smoker & & \\
\hline
\end{tabular}

Table (1) showed that the mean age \pm standard deviation (SD) was $26.6 \pm 8.6$ years. The highest percentage of workers $(44.0 \%)$ was in the age group 20-40 years, while the lowest percentage $(17.2 \%)$ was $<20$ years. The majority of them was from urban areas $(56.9 \%)$ and was single $(52.6 \%)$. Those with basic education constituted $(32.8 \%)$, while illiterates constituted $19.8 \%$, and those graduated from secondary/technical schools constituted $47.1 \%$. As regard smoking, 56 workers $(48.3 \%)$ were current smokers. 
Table 2. Distribution of the study group according to occupational history

\begin{tabular}{|l|c|c|}
\hline Occupational history & No. & $\%$ \\
\hline Job & & \\
Electricians & 11 & 9.5 \\
Bricklayers\& concrete finishers & 33 & 28.4 \\
Plumbers & 14 & 12.1 \\
Elevator constructors & 24 & 20.7 \\
Installers of floors & 16 & 13.8 \\
Painters & 13 & 11.2 \\
Carpenters & 5 & 4.3 \\
\hline Duration of work (yrs) & & \\
$<5$ & 42 & 36.2 \\
$5-10$ & 48 & 41.4 \\
$>10$ & 26 & 22.4 \\
\hline Working hours (h/d) & & \\
$<8$ & 16 & 13.8 \\
$\geq 8$ & 100 & 86.2 \\
\hline
\end{tabular}

Table 2 showed that the highest percentage of participants was bricklayers and concrete finishers workers $(28.4 \%)$ and only (4.3\%) were carpenters. The highest percentage of workers $(41.4 \%)$ had duration of work 5- 10 years and $86.2 \%$ of workers were working for more than 8 hours/ day. All participants were daytime workers with no shift work. 
Table 3. Prevalence of CTS among construction workers according job categories.

\begin{tabular}{|l|c|c|c|c|}
\hline \multirow{2}{*}{ Job } & \multicolumn{2}{|c|}{ Yes } & \multirow{2}{*}{ X2 } & \multirow{2}{*}{ P-value } \\
\cline { 2 - 3 } & $\mathrm{N}$ & $\%$ & & \multirow{2}{*}{0.02} \\
\hline Electricians & 7 & 63.3 & 14.86 & \\
\hline Bricklayers, concrete finishers & 8 & 24.2 & & \\
\hline Plumbers & 3 & 21.4 & & \\
\hline Elevator constructors & 2 & 8.3 & & \\
\hline Installers of floors & 5 & 31.2 & & \\
\hline Painters & 4 & 30.8 & & \\
\hline Carpenters & 3 & 60.0 & & \\
\hline Overall & 32 & 27.6 & & \\
\hline
\end{tabular}

Table 3 showed that the allover prevalence of CTS among construction workers was $27.6 \%$. The highest prevalence of CTS was among electricians (63.3\%), followed by carpenters $(60.0 \%)$. The lowest prevalence was among elevator constructors $(8.3 \%)$. The difference among different job categories was statistically significant $(\mathrm{P}<0.05)$. 
Table 4. Distribution of workers with CTS

\begin{tabular}{|l|c|c|}
\hline \multirow{2}{*}{ Symptoms Experienced } & \multicolumn{2}{|c|}{ (CTS (N=32 } \\
\cline { 2 - 3 } & $\mathrm{N}$ & $\%$ \\
\hline Types (not mutually exclusive & 6 & 18.8 \\
Parasthesia & 30 & 93.8 \\
Pain in hand/wrist & 21 & 65.6 \\
Numbness & 9 & 28.1 \\
Decrease of hand muscular power & 18 & 56.3 \\
Nocturnal exacerbations of symptoms & & \\
\hline Frequency of symptoms & 12 & 37.5 \\
Always & 18 & 56.2 \\
Occasionally & 2 & 6.3 \\
Rare & & \\
\hline (Duration of symptoms (yrs & 12 & 39.5 \\
1> & 1 & 44.9 \\
$31-$ & 5 & 15.6 \\
$3<$ & & \\
\hline Sick leave taking & 12 & 37.5 \\
Yes & 20 & 62.5 \\
No & & \\
\hline Treatment taking & 24 & 75 \\
Yes & & \\
No & & \\
\hline
\end{tabular}

Table 4 showed that $93.8 \%$ of workers diagnosed with CTS had pain, $65.6 \%$ had numbness and $56.2 \%$ of them were occasionally experienced these symptoms. Twelve workers $(37.5 \%)$ diagnosed with CTS take sick leave because of CTS symptoms and a small percentage $(25 \%)$ was taking medical treatment for CTS. 
Abdellah RF et al.,

Table 5. Bivariate analysis of risk factors of CTS among construction workers.

\begin{tabular}{|c|c|c|c|c|c|c|c|}
\hline \multirow[b]{3}{*}{ Variables } & \multicolumn{4}{|c|}{ CTS } & \multirow[b]{3}{*}{ OR } & \multirow[b]{3}{*}{$95 \% \mathrm{CI}$} & \multirow[b]{3}{*}{ P-value } \\
\hline & \multicolumn{2}{|c|}{ No } & \multicolumn{2}{|c|}{ Yes } & & & \\
\hline & $\mathrm{N}$ & $\%$ & $\mathrm{~N}$ & $\%$ & & & \\
\hline Age & & & 13 & & \multirow[b]{3}{*}{3.2} & \multirow{3}{*}{$\begin{array}{l}1.40- \\
7.57\end{array}$} & \multirow[b]{3}{*}{0.005} \\
\hline$<30$ & 58 & 81.7 & 19 & 18.3 & & & \\
\hline$\geq 30$ & 26 & 57.7 & & 42.3 & & & \\
\hline Current smokers & & & & & & \multirow{3}{*}{$\begin{array}{c}0.67- \\
3.49\end{array}$} & \multirow[b]{3}{*}{0.31} \\
\hline No & 43 & 76.8 & 13 & 23.2 & \multirow[b]{2}{*}{1.53} & & \\
\hline Yes & 41 & 68.3 & 19 & 31.7 & & & \\
\hline \multirow{3}{*}{$\begin{array}{l}\text { Duration of } \\
\text { employment } \\
\quad<5 \\
\geq 5\end{array}$} & & & & & \multirow[b]{3}{*}{4.25} & \multirow{3}{*}{$\begin{array}{l}1.49- \\
12.11\end{array}$} & \multirow[b]{3}{*}{0.002} \\
\hline & 37 & 88.1 & 5 & 11.9 & & & \\
\hline & 47 & 63.3 & 27 & 36.4 & & & \\
\hline \multirow[t]{3}{*}{ Work hours/day } & & & & & & \multirow{3}{*}{$\begin{array}{c}0.26- \\
2.56\end{array}$} & \multirow[b]{3}{*}{0.72} \\
\hline & 11 & 68.8 & 5 & 31.3 & & & \\
\hline & 73 & 73.0 & 27 & 27.0 & 0.81 & & \\
\hline
\end{tabular}

Table 5 showed that CTS is more prevalent among those age $\geq 30$ years and among those working for $\geq 5$ years. The difference is significantly $(\mathrm{P}<0.05)$. Also, the percentage of CTS was higher among current smokers $(31.7 \%)$ than among non-smokers (23.2\%), the difference was statistically insignificantly $(\mathrm{P}>0.05)$. 


\section{Discussion}

This study was carried on 116 of workers in construction industry. Our study results revealed that out of total participants, $27.6 \%$ of the construction workers experienced CTS. This is similar to the prevalence rate found in France (19.7\%) (Roquelaure et al.,2009) and $(21 \%)$ in Hungary (Rosecrance et al. 2001) . This high prevalence of CTS among construction workers can be due to the higher prevalence of repetitive movements of the hand or wrist, forceful handgrip and loads handling during works. Hunting et al., 1994 in a study of 308 electricians, reported a higher prevalence where $47 \%$ of them had wrist symptoms representative of cumulative trauma disorders.

The use of vibrating tools increases the risk of CTS development. Vibration of hand tools affects blood circulation and cause wrist and hand disorders (Barcenilla et al., 2012). It seems that when work rate increases, repetition of hand or wrist increases and as a result, the risk of CTS development increases (Shiri et al., 2009).

The prevalence of CTS in our study was higher than that in other industrial setting (6-15\%) (Ghasemi et al., 2012). In Iran, 395 workers from automobile industry factories were assessed by interview and electrodiagnostic studies, 47 met the definition of CTS to yield a prevalence of $11.9 \%$ (Maghsoudipour et al., 2008). In German, the prevalence of CTS in working populations $(10.9 \%)$ was significantly higher than in the general population (8.2\%) (Spahn et al., 2012). This discrepancy in the prevalence may be linked to the difference between countries in level of development, and strengths of occupational health and safety services and the use of electrodiagnostic studies. It can be expected that the prevalence of CTS would decrease if clinical diagnosis and/or nerve conduction testing were used to validate the estimate (Lenderink, 2012 and Raman et al, 2012).

The most frequently reported CTS symptoms in our study were in the following order: hand/wrist pain in $93.8 \%$, numbness in $65.6 \%$, nocturnal exacerbations in $56.3 \%$ of workers. When we compare these findings to those presented by Ahamed et al (2015) we find that they reported the same symptoms but with lesser percentages. 
There are some personnel and occupations risk factor that predispose to CTS. In our study, the prevalence of CTS was higher in older age group $\geq$ 30 (table 5). In most literature reviews, the prevalence of CTS increased in patients 40-60 years old (Ghasemiet al., 2012 and Harris-Adamson et al., 2013). The difference in smoking habits was not statistically significant in the development of CTS (table 5). This finding is concoid with Armstrong et al (2008). Also, CTS is associated with longer duration of work $(\mathrm{P}<0.05)$ but not with working hours $(\mathrm{P}>0.05)$. This agree with the results of study conducted on 996 construction workers, where longer duration of work has been found as a risk factor for CTS (Merlino, et al., 2003).

\section{Conclusion}

Based on the results of our study, together with the documented high prevalence of factors associated with CTS may indicate that programs for the identification, prevention and intervention of musculoskeletal conditions such as CTS should specifically target this risk group.

\section{Conflict of Interest:}

Authors have declared that no conflict of interests exists.

\section{References}

1. Ahamed S, Anas M, Aref A, et al (2015): Prevalence and associated factors of Carpal Tunnel Syndrome (CTS) among medical laboratory staff at King Saud University Hospitals, KSA. Pak J Med Sci.; 31(2):331-5.

2. Adane M, Gelaye K, Beyera G et al. (2013): Occupational Injuries Among Building Construction Workers in Gondar City, Ethiopia. Occup Med Health Aff; 1(5): 1-5.

3. Armstrong $\mathrm{T}$, Dale AM, Franzblau A, et al. (2008): Risk factors for carpal tunnel syndrome and median neuropathy in a working population. J Occup Environ Med ; 50(12) :1355-64.

4. Barcenilla A, March LM, Chen JS, et al (2012): Carpal tunnel syndrome and its relationship to occupation: a meta-analysis. Rheumatology; 51(2):250-61.

5. Boschman J, Frings-Dresen M, Van der Molen H (2015). Use of Ergonomic Measures Related to Musculoskeletal Complaints among Construction Workers: A 2-year Follow-up Study. Saf Health Work.; 6(2):90-6.

6. Dale AM, Harris-Adamson C, Rempel D et al. (2013): Prevalence and incidence of carpal tunnel syndrome in US working populations: pooled analysis of six prospective studies. Scand J Work Environ Health; 39(5): 495-505.

7. Dean J, Dean D, Coulombeir K, et al. (2001): "Epi- info Version 6: A Word Processing Data Base and Statistics Program for Epidemiology on Microcomputers," Center for Disease Control, Atlanta.

8. Foley M, Silverstein B, Polissar N (2007). The economic burden of carpal tunnel syndrome: 
long-term earnings of CTS claimants in Washington State. Am J Ind Med; 50(3):15572.

9. Ghasemi M, Rezaee M, Chavoshi $F$ et al. (2012): Carpal Tunnel Syndrome: The Role of Occupational Factors Among 906 Workers. Trauma Mon; 17(2): 296-300.

10. Harris-Adamson C, Eisen E, Dale A et al (2013). Personal and workplace psychosocial risk factors for carpal tunnel syndrome: a pooled study cohort. Occup Environ Med.; 70(8):529-37.

11. Harris-Adamson C, Eisen E, Kapellusch J et al (2015): Biomechanical risk factors for carpal tunnel syndrome: a pooled study of 2474 workers. Occup Environ Med.; 72(1):33-41.

12. Hunting K, Welch L, Cuccherini B et al (1994): Musculoskeletal symptoms among electricians. Am J Indus Med; 25:149-163.

13. Jagga V, Lehri A and Verma S (2011): Occupation and its association with Carpal Tunnel syndrome- A Review. Journal of Exercise Science and Physiotherapy, 7(2) : 6878.

14. Lenderink A, Zoer I, van der Molen H, et al. (2012): Review on the validity of self report to assess work related diseases. Int Arch Occup Environ Health; 85:229-251.

15. Maghsoudipour M, Moghimi S, Dehghaan F, et al. (2008): Association of occupational and nonoccupational risk factors with the prevalence of work related carpal tunnel syndrome. J Occup Rehabil; 18(2): 152-6.

16. Merlino L, Rosecrance J, Anton D, et al (2003). Symptoms of musculoskeletal disorders among apprentice construction workers. Appl Occup Environ Hyg; 18(1):57-64.
17. Raman SR1, Al-Halabi B, Hamdan E, et al. (2012): Prevalence and risk factors associated with self-reported carpal tunnel syndrome (CTS) among office workers in Kuwait. BMC Res Notes; 13(5):289.

18. Roquelaure $\mathrm{Y}$, Catherine $\mathrm{H}$, Nicolas $\mathrm{G}$, et al (2008): Attributable risk of carpal tunnel syndrome according to industry and occupation in a general population. Arthritis Rheum; 15;59(9):1341-8.

19. Roquelaure Y, Ha C, Fouquet N, et al., (2009): Attributable risk of carpal tunnel syndrome in the general population: implications for intervention programs in the workplace. Scand J Work Environ Health. ; 35(5):342-8.

20. Rosecrance J, Pórszász J, Cook T, et al. (2001): Musculoskeletal disorders among construction apprentices in Hungary. Cent Eur J Public Health; 9(4):183-7.

21. Shiri R, Miranda H, Heliovaara M, et al (2009). Physical workload factors and carpal tunnel syndrome: a population-based study. Occup Environ Med; 66(6): 368-73.

22. Silverstein BA, Fine LJ and Armstrong TJ (1987). Occupational factors and carpal tunnel syndrome. Am J Ind Med; 11(3): 343-58.

23. Sluiter JK, Rest KM and Frings-Dresen MH (2001): Criteria document for evaluating the work-relatedness of upper-extremity musculoskeletal disorders. Scand J Work Environ Health; 27(1):1- 102.

24. Spahn G, Wollny J, Hartmann B et al (2012): Metaanalysis for the evaluation of risk factors for carpal tunnel syndrome. Z Orthop Unfall; 150(5): 516-24. 